\title{
Inquérito sorológico da infecção pelos vírus da encefalomielite equina no estado de Minas Gerais, Brasil
}

\author{
Serological survey of equine encephalomyelitis virus infection \\ in the state of Minas Gerais, Brazil
}

\author{
Maria do Carmo Custódio de Souza Hunold LARA; Glaucia BEGHIN²; \\ Elenice Maria Sequetin CUNHA ${ }^{1}$; Eliana Monteforte Cassaro VILLALOBOS ${ }^{1}$; \\ Alessandra Figueiredo de Castro NASSAR ${ }^{1}$; Ana Cristina Passos de Paiva BELLO ${ }^{3}$; \\ Arildo Pinto CUNHA ${ }^{3}$; Jenner Karlisson Pimenta dos REIS ${ }^{3}$; Rômulo Cerqueira LEITE3; Enio MORI ${ }^{4}$ \\ ${ }^{1}$ Instituto Biológico, São Paulo - SP, Brasil \\ ${ }^{2}$ Bolsista PIBIC-CNPq \\ ${ }^{3}$ Universidade Federal de Minas Gerais, Belo Horizonte - MG, Brasil \\ ${ }^{4}$ Instituto Pasteur, São Paulo - SP, Brasil
}

\begin{abstract}
Resumo
Foi investigada a ocorrência da infecção pelos vírus da Encelafalomielite Equina do Leste (EEE), Encefalomielite Equina do Oeste (WEE) e Encefalomielite Equina Venezuelana (VEE) em equídeos não vacinados contra tais agentes, criados em dez delegacias regionais do estado de Minas Gerais (Almenara, Bambuí, Curvelo, Governador Valadares, Montes Claros, Oliveira, São Gonçalo do Sapucaí, Teófilo Otoni, Unaí e Viçosa), empregando-se a técnica de soroneutralização em microplacas. Dos 826 animais examinados, 30,2\% (250/826) foram soropositivos para o EEE e 1,9\% (16/826) para o VEE. Não foram detectados animais sororreagentes para o WEE. Conclui-se que tanto o vírus tipo leste como o venezuelano da Encelafalomielite Equina circulam na população equina do estado de Minas Gerais.
\end{abstract}

Palavras-chave: Equídeos. Estado de Minas Gerais. Encefalomielite equina.

\begin{abstract}
The occurrence of Equine Eastern Encephalomyelitis (EEE), Equine Western Encephalomyelitis (WEE) and Equine Venezuelan Encephalomyelitis (VEE) virus infection was investigated in equids not vaccinated against these viruses. The animals were distributed in ten regional districts of the state of Minas Gerais (Almenara, Bambuí, Curvelo, Governador Valadares, Montes Claros, Oliveira, São Gonçalo do Sapucaí, Teófilo Otoni, Unaí e Viçosa). Microplate serum neutralization test was used to detect antibodies against encephalitis virus. Two hundred and fifty animals $(30.2 \%, 250 / 826)$ were EEE-seropositive, while $1.9 \%$ of them $(16 / 826)$ were VEE-seropositive. No animals were found to be seropositive for WEE. In conclusion, either EEE or VEE viruses circulate in the equid population of the state of Minas Gerais.
\end{abstract}

Keywords: Equids. State of Minas Gerais. Equine Encephalomyelitis.

\section{Introdução}

Encefalomielite Equina é uma doença causada por três espécies de vírus, transmitida por mosquitos, provocando quadro neurológico em diversas espécies animais e humanos. Os agentes pertencem ao gênero Alphavirus e estão envolvidos em três formas da doença: Encelafalomielite Equina Leste (EEE), Encefalomielite Equina Oeste (WEE) e Encefalomielite Equina Venezuelana (VEE) (ACHA; SZYFRES, 2003).

A via de transmissão é indireta e os vetores são os mosquitos Culex spp. e Aedes spp. A via de eliminação é o sangue e as fontes de infecção para a EEE e WEE são as aves silvestres, já para a VEE são os equinos e os roedores silvestres. O período de incubação é de aproximadamente sete dias, sendo o tipo leste de alta

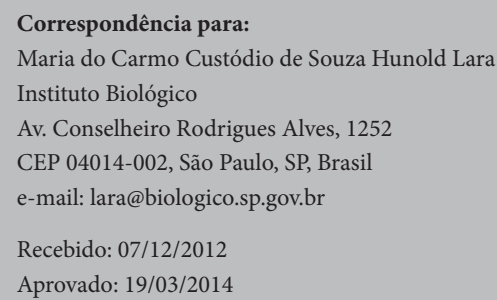


letalidade (75-90\% em equinos e 30-65\% em humanos) e os demais possuem letalidade baixa, podendo existir casos de infecção inaparente. Os vírus acometem o sistema nervoso, provocando reação inflamatória viral típica (ACHA; SZYFRES, 2003).

Os sintomas em humanos são febre, cefaleia, conjuntivite, emese, rigidez na nuca, letargia, podendo haver melhora do paciente ou rápida progressão, levando-o à confusão mental e coma. Em animais, o quadro é semelhante, caracterizado por depressão, lábios flácidos, andar em círculos, bater em obstáculos, incoordenação motora, sonolência e letargia (ACHA; SZYFRES, 2003; CARNEIRO, 1937).

No Brasil, há poucos estudos investigando a ocorrência de Alphavirus em equídeos (LOPES; SACCHETA, 1974; KOTAIT et al., 1992; IVERSSON et al., 1993; SILVA et al., 1999; FERNÁNDEZ et al., 2000; HEINEMANN et al., 2006; AGUIAR et al., 2008; CUNHA et al., 2009; SILVA et al., 2011; CAMPOS et al., 2013), apesar de ser conhecido que alguns vírus desta família são endêmicos em várias regiões, como por exemplo, nas regiões amazônica e pantaneira, que oferecem condições ecológicas favoráveis para a manutenção dos vírus EEE, WEE e VEE, pois apresentam ampla variedade de aves nativas e migratórias, além da existência local de insetos vetores (HEINEMANN et al., 2006; IVERSSON; COIMBRA, 1984; VASCONCELOS et al., 1991).

$\mathrm{O}$ vírus da encefalomielite equina tipo leste já foi isolado de equinos com sintomatologia neurológica no estado de São Paulo (CARNEIRO, 1937; KOTAIT et al., 1992; NILSSON; SUGAY, 1962). No estado do Rio de Janeiro, o vírus tipo leste foi detectado pela técnica de PCR em amostras de sistema nervoso central de dois equinos que apresentaram quadro neurológico (BRANDÃO et al., 2004). Na região do Vale do Ribeira do estado de São Paulo, no período de 2004 a 2005 , foram constatadas prevalências de $16 \%$ contra o vírus EEE e 2,26\% contra o VEE, em equídeos (CUNHA et al., 2009).
Considerando a ausência de investigações sobre a ocorrência de encefalites causadas por Alphavirus em equídeos no estado de Minas Gerais, o presente trabalho foi delineado para verificar a frequência de ocorrência de anticorpos para EEE, WEE e VEE em equídeos não vacinados contra tais vírus e criados em distintas regiões do referido estado.

\section{Material e Método}

Durante o ano de 2002, foram colhidas amostras de soro sanguíneo de 826 equídeos não vacinados contra os vírus da encefalomielite equina, distribuídos em dez delegacias regionais do estado de Minas Gerais (Almenara, Bambuí, Curvelo, Governador Valadares, Montes Claros, Oliveira, São Gonçalo do Sapucaí, Teófilo Otoni, Unaí e Viçosa). As amostras de sangue foram obtidas assepticamente por punção da veia jugular externa e os soros obtidos após retração do coágulo e estocados a $-20^{\circ} \mathrm{C}$ até a realização das provas laboratoriais.

Para a pesquisa de anticorpos neutralizantes contra os vírus da EEE, WEE e VEE foi utilizada a técnica de soroneutralização (SN), segundo Cunha et al. (2009). Os soros foram testados em diluições na base 5 para detecção de anticorpos contra EEE, WEE, VEE frente a $100 \mathrm{DICT}_{50} / 25 \mu \mathrm{l}$ de suspensão dos vírus leste (amostra Tatuí), oeste (amostra TR 25717) e complexo venezuelano (amostra SP AN 15600), mantidos no Instituto Biológico de São Paulo. Após a incubação, por uma hora a $37^{\circ} \mathrm{C}$, foram adicionados $100 \mu \mathrm{l}$ de uma suspensão de células VERO para os testes de EEE, WEE e VEE, contendo 250.000 células/ml. A leitura das placas para a técnica de $\mathrm{SN}$ foi realizada após 72 horas de incubação, em estufa com 5\% de $\mathrm{CO}_{2}$ e a $37^{\circ} \mathrm{C}$, observando-se a neutralização do efeito citopático. Os títulos de anticorpos neutralizantes foram expressos em valores do inverso da diluição que neutralizou $100 \mathrm{DICT}_{50}$ do vírus. Foram considerados reagentes os soros com título $\geq$ a 5 para os vírus EEE, WEE e VEE, conforme recomendação da OIE. 


\section{Resultados e Discussão}

Não foram detectados animais reagentes para WEE, concordando com os achados de Aguiar et al. (2008) e Cunha et al. (2009), no estado de Rondônia e no sul do estado de São Paulo, respectivamente; e discordando dos resultados encontrados por Silva et al. (1999) e Heinemann et al. (2006), que relataram frequências de 1,2\% no Pantanal Mato-Grossense e 1,05\% no sul do estado do Pará, respectivamente.

Os resultados apresentados neste estudo detectaram anticorpos contra o vírus da VEE, ocorrendo 1,9\% (16/826) de positividade para equídeos, e corroboram com os achados por Cunha et al. (2009) de 2,26\% no sul do estado de São Paulo. Os achados de Aguiar et al. (2008) foram um pouco mais elevados, com 11,3\% de soropositividade em equídeos criados em Rondônia.

Do total de 826 animais examinados, 30,2\% (250/826) foram sororreagentes ao vírus da EEE. Esse resultado é semelhante aos relatados por Heinemann et al. (2006) e Aguiar et al. (2008), que encontraram frequências de 27,37\% no sul do estado do Pará e 21,0\% no Pantanal Mato-Grossense, respectivamente. Cunha et al. (2009), trabalhando com equídeos criados no sul do Estado de São Paulo, encontraram frequência de $16 \%$ para o EEE, resultados menores que os encontrados neste trabalho. Valores superiores aos encontrados neste estudo foram observados no sul do Pantanal Mato-Grossense, na região de Nhecolândia, com $47,7 \%$ de equinos sororreagentes ao EEE (PAUVOLID-CORRÊA et al., 2010), e também no estado da Paraíba, com frequência de $63,3 \%$ para o EEE (ARAÚJO et al., 2012).

Além disso, com os resultados obtidos na presente pesquisa, como pode ser observado na Tabela 1, o EEE encontra-se amplamente disseminado no estado de Minas Gerais, pois todas as regiões estudadas apresentaram animais sororreagentes. Frente aos diferentes ecossistemas, não foi constatada diferença entre os biomas, sugerindo que o EEE esteja adaptado e circule entre os mesmos (Tabela 2). Diferentemente, o VEE se encontra presente somente em regiões distintas (distritos de Curvelo e Anaí) do bioma cerrado (Tabelas 1 e 2).

No presente trabalho, a maioria dos animais positivos (75\% para VEE e 77,2\% para EEE) encontravase acima da faixa de quatro anos, provavelmente em função do maior tempo de exposição destes animais aos agentes virais.

A confirmação da presença de anticorpos anti-EEE e anti-VEE no estado de Minas Gerais, nesse primei-

Tabela 1 - Ocorrência da infecção por EEE e VEE determinada pela reação de soroneutralização em microplacas em soro sanguíneo de equídeos criados no estado de Minas Gerais, Brasil, segundo a procedência das amostras e espécie animal. Colheitas de sangue efetuadas durante o ano de 2002

\begin{tabular}{|c|c|c|c|c|c|c|c|c|c|c|c|c|}
\hline \multirow[b]{2}{*}{ Delegacias Regionais } & \multirow[b]{2}{*}{ Total } & \multicolumn{3}{|c|}{$\mathrm{N}$. de animais } & \multirow[b]{2}{*}{ Total } & \multicolumn{3}{|c|}{ VEE } & \multirow[b]{2}{*}{ Total } & \multicolumn{3}{|c|}{ EEE } \\
\hline & & $\begin{array}{c}\text { Equino } \\
(\%)\end{array}$ & $\begin{array}{c}\text { Asinino } \\
(\%)\end{array}$ & $\begin{array}{c}\text { Muar } \\
(\%)\end{array}$ & & $\begin{array}{c}\text { Equino } \\
(\%)\end{array}$ & $\begin{array}{c}\text { Asinino } \\
(\%)\end{array}$ & $\begin{array}{c}\text { Muar } \\
(\%)\end{array}$ & & $\begin{array}{c}\text { Equino } \\
(\%)\end{array}$ & $\begin{array}{c}\text { Asinino } \\
(\%)\end{array}$ & $\begin{array}{c}\text { Muar } \\
(\%)\end{array}$ \\
\hline Almenara & 130 & $118(15,7)$ & $1(25)$ & $11(15,1)$ & 0 & $0(0)$ & $0(0)$ & $0(0)$ & 50 & $49(20,7)$ & $0(0)$ & $1(7,1)$ \\
\hline Bambuí & 44 & $37(4,9)$ & $1(25)$ & $6(8,2)$ & 0 & $0(0)$ & $0(0)$ & $0(0)$ & 19 & $15(6,3)$ & $0(0)$ & $4(28,6)$ \\
\hline Curvelo & 88 & $78(10,4)$ & $0(0)$ & $10(13,7)$ & 4 & $4(36,3)$ & $0(0)$ & $0(0)$ & 37 & $36(15,2)$ & $0(0)$ & $1(7,1)$ \\
\hline Governador Valadares & 47 & $44(5,8)$ & $1(25)$ & $2(2,7)$ & 0 & $0(0)$ & $0(0)$ & $0(0)$ & 6 & $6(2,5)$ & $0(0)$ & $0(0)$ \\
\hline Montes Claros & 92 & $81(10,8)$ & $0(0)$ & $11(15,1)$ & 0 & $0(0)$ & $0(0)$ & $0(0)$ & 15 & $14(5,9)$ & $0(0)$ & $1(7,1)$ \\
\hline Oliveira & 47 & $46(6,1)$ & $1(25)$ & $0(0)$ & 0 & $0(0)$ & $0(0)$ & $0(0)$ & 9 & $9(3,8)$ & $0(0)$ & $0(0)$ \\
\hline São Gonçalo do Sapucaí & 45 & $45(6,0)$ & $0(0)$ & $0(0)$ & 0 & $0(0)$ & $0(0)$ & $0(0)$ & 12 & $12(5,1)$ & $0(0)$ & $0(0)$ \\
\hline Teófilo Otoni & 147 & $133(17,7)$ & $0(0)$ & $14(19,2)$ & 0 & $0(0)$ & $0(0)$ & $0(0)$ & 45 & $43(18,2)$ & $0(0)$ & $2(14,3)$ \\
\hline Unaí & 128 & $113(15,0)$ & $0(0)$ & $15(20,5)$ & 12 & $7(63,6)$ & $0(0)$ & $5(100)$ & 38 & $34(14,4)$ & $0(0)$ & $4(28,6)$ \\
\hline Viçosa & 58 & $54(7,2)$ & $0(0)$ & $4(5,5)$ & 0 & $0(0)$ & $0(0)$ & $0(0)$ & 19 & $18(7,6)$ & $0(0)$ & $1(7,1)$ \\
\hline TOTAL & 826 & 749 & 4 & 73 & 16 & 11 & 0 & 5 & 250 & 236 & 0 & 14 \\
\hline
\end{tabular}


Tabela 2 - Número e frequência de equídeos positivos para os vírus da Encefalomielite Equina Leste (EEE) e Venezuelana (VEE) por municípios avaliados nos biomas Mata Atlântica, Cerrado e Caatinga no estado de Minas Gerais. Colheitas de sangue efetuadas em 2002

\begin{tabular}{|c|c|c|c|c|c|c|c|c|}
\hline \multirow{3}{*}{ Bioma } & \multirow{3}{*}{ Espécie } & \multirow{3}{*}{$\begin{array}{l}\text { Número de } \\
\text { animais } \\
\text { testados }\end{array}$} & \multicolumn{6}{|c|}{ Número de animais reagentes } \\
\hline & & & \multicolumn{2}{|c|}{ EEE } & \multicolumn{2}{|c|}{ VEE } & \multicolumn{2}{|c|}{ EEE-VEE } \\
\hline & & & $\mathbf{n}$ & $\%$ & $\mathbf{n}$ & $\%$ & $\mathbf{n}$ & $\%$ \\
\hline \multirow[t]{4}{*}{ Cerrado } & Equino & 335 & 100 & 29,8 & 11 & 3,3 & 4 & 4,1 \\
\hline & Muar & 39 & 9 & 23,1 & 5 & 12,8 & 0 & 0 \\
\hline & Asinino & 2 & 0 & 0 & 0 & 0 & 0 & 0 \\
\hline & Subtotal & 376 & 109 & 29,0 & 16 & 4,2 & 4 & 1,1 \\
\hline \multirow[t]{4}{*}{ Mata Atlântica } & Equino & 355 & 117 & 32,9 & 0 & 0 & 0 & 0 \\
\hline & Muar & 24 & 4 & 16,7 & 0 & 0 & 0 & 0 \\
\hline & Asinino & 1 & 0 & 0 & 0 & 0 & 0 & 0 \\
\hline & Subtotal & 380 & 121 & 31,8 & 0 & 0 & 0 & 0 \\
\hline \multirow[t]{4}{*}{ Caatinga } & Equino & 59 & 20 & 33,9 & 0 & 0 & 0 & 0 \\
\hline & Muar & 10 & 0 & 0 & 0 & 0 & 0 & 0 \\
\hline & Asinino & 1 & 0 & 0 & 0 & 0 & 0 & 0 \\
\hline & Subtotal & 70 & 20 & 28,6 & 0 & 0 & 0 & 0 \\
\hline Total & & 826 & 250 & 30,2 & 16 & 1,9 & 4 & 0,5 \\
\hline
\end{tabular}

ro relato de literatura, deve ser considerado como fator epidemiológico importante. Devido aos equídeos apresentarem grande suscetibilidade a esses agentes virais, esses achados enfatizam a importância desses animais serem utilizados como indicadores ou sentinelas para monitorar a circulação de arbovírus nesse estado.

\section{Conclusão}

Como os soros sanguíneos foram colhidos de equídeos hígidos e não vacinados contra a encefalomielite equina, pode-se concluir que tanto o vírus tipo leste como o venezuelano da encefalomielite equina estão presentes no estado de Minas Gerais, pois 30,2\% dos animais apresentaram anticorpos contra o EEE e 1,9\% apresentou anticorpos contra o VEE. 


\section{Referências}

ACHA, P. N.; SZYFRES, B. Zoonosis y enfermedades comunes al hombre y a los animales: clamidiosis, rickettsiosis y virosis. 3 . ed. Washington, D.C.: Organización Panamericana de la Salud, 2003. 425 p.

AGUiAR, D. M.; CAVALCANTE, G. T.; LARA, M. C. C. S. H.; VILLALOBOS, E. M. C.; CUNHA, E. M. S.; OKUDA, L. H.; ESTEFANO, E.; NASSAR, A. F. C.; VASCONCELLOS, S. A.; LABRUNA, M. B.; CAMARGO, L. M. A.; GENNARI, S. M. Prevalência de anticorpos contra agentes virais e bacterianos em eqüídeos do município de Monte Negro, Rondônia. Amazônia Ocidental Brasileira. Brazilian Journal of Veterinary Research and Animal Science, v. 45, n. 4, p. 269-276, 2008.

ARAÚJO, F. A. A.; ANDRADE, M. A.; JAYME, V. S.; SANTOS, A. L.; ROMANO, A. P. M.; RAMOS, D. G.; CUNHA, E. M. S.; FERREIRA, M. S.; LARA, M. C. C. S. H.; VILLALOBOS, E. M. C.; MARTINS, L. C. Anticorpos antialfavírus detectados em equinos durante diferentes epizootias de encefalite equina, Paraíba, 2009. Revista Brasileira de Ciência Veterinária, v. 19, n. 1, p. 80-85, 2012.

BRANDÃO, P. E.; FREITAS, P. H. B.; OLIVEIRA, M. V. S.; JEREZ, J. A.; CARRIERI, M. L.; KOTAIT, I. Detection of eastern equine encephalitis virus (Togaviridae: Alphavirus) in an outbreak of encephalitic disease in horses. Virus Reviews and Research, v. 9, p. 124, 2004. Suppl. 1.

CAMPOS, K. F.; OLIVEIRA, C. H. S.; REIS, A. B.; YAMASAKI, E. M.; BRITO, M. F.; ANDRADE, S. J. T.; DUARTE, M. D.; BARBOSA, J. D. Surto de encefalomielite equina Leste na Ilha de Marajó, Pará. Pesquisa Veterinária Brasileira, v. 33, n. 4, p. 443 448,2013

CARNEIRO, V. A encefalomielite infecciosa dos eqüídeos do Brasil. Arquivos do Instituto Biológico, v. 8, p. 115-134, 1937.

CUNHA, E. M. S.; VILALLOBOS, E. M. C.; NASSAR, A. F. C.; LARA, M. C. C. S. H.; PERES, N. F.; PALAZZO, J.; SILVA, A.; PINO, F. A. Prevalência de anticorpos contra agentes virais em eqüídeos no sul do estado de São Paulo. Arquivos do Instituto Biológico, v. 76, n. 2, p. 165-171, 2009.

FERNÁNDEZ, Z.; RICHARTZ, R.; TRAVASSOS DA ROSA, A. P. A.; SOCCOL, V. T. Identificação do vírus causador de encefalomielite eqüina, Paraná, Brasil. Revista de Saúde Pública, v. 34, n. 3, p. 232-235, 2000.

HEINEMANN, M. B.; SOUZA, M. C. C.; CORTEZ, A.; FERREIRA, F.; HOMEM, V. S. F.; FERREIRA NETO, J. S.; SOARES, R. M.; CUNHA, E. M. S.; RICHTZENHAIN, J. L. Soroprevalência da encefalomielite eqüina do leste e oeste no município de Uruará,
PA, Brasil. Brazilian Journal of Veterinary Research and Animal Science, v. 43, p. 137-139, 2006. Supplement.

IVERSSON, L. B.; COIMBRA, T. L. M. Encefalite na região do Vale do Ribeira, São Paulo, Brasil, no período pós-epidêmico de 1978 a 1983. Revista de Saúde Pública, v. 18, p. 323-332, 1984.

IVERSSON, L. B.; SILVA, M. S.; TRAVASSOS DA ROSA, A. P. A.; BARROS, R. S. V. Circulation of Eastern equine encephalitis, Western equine encephalitis, Ilhéus, Maguari e Tacaiuma viruses in equines of the Brazilian Pantanal, South America. Revista do Instituto de Medicina Tropical de São Paulo, v. 35, n. 4, p. 355$359,1993$.

KOTAIT, I.; PEIXOTO, Z. M. P.; COIMBRA, T. L. M.; CUNHA, E. M. S.; QUEIROZ, L. H.; MACRUZ, R.; NAGAMORI, A. H. Isolamento e identificação do vírus da encefalomielite eqüina, tipo leste, em eqüinos do estado de São Paulo, Brasil. Arquivos do Instituto Biológico, v. 59, n. 1/2, p. 37-41, 1992.

LOPES, O. S.; SACCHETA, A. Epidemiological studies on eastern equine encephalitis virus in São Paulo, Brazil. Revista do Instituto de Medicina Tropical de São Paulo, v. 16, n. 5, p. 253-258, 1974.

NILSSON, M. R.;SUGAY, W. Ocorrência da encefalomielite eqüina em Itaporanga, estado de São Paulo. Arquivos do Instituto Biológico, v. 29, p. 63-68, 1962.

PAUVOLID-CORRÊA, A.; TAVARES, F. N.; COSTA, E. V.; BURLANDY, F. M.; MURTA, M.; PELLEGRIN, A. O.; NOGUEIRA, M. F.; SILVA, E. E. Serologic evidence of the recent circulation of Saint Louis encephalitis virus and high prevalence of equine encephalitis viruses in horses in the Nhecolândia subregion in South Pantanal, Central-West Brazil. Memórias do Instituto Oswaldo Cruz, v. 105, n. 6, p. 829-833, 2010.

SILVA, M. L. C. R.; GALIZA, G. J. N.; DANTAS, A. F. M.; OLIVEIRA, R. N.; IAMAMOTO, K.; ACHKAR, S. M.; RIETCORREA, F. Outbreaks of Eastern equine encephalitis in northeastern Brazil. Journal of Veterinary Diagnostic Investigation, v. 23, n. 3, p. 570-575, 2011.

SILVA, R. A. M. S.; DÁVILA, A. M. R.; IVERSSON, L. B.; ABREU, U. G. P. Equine viral diseases in the Pantanal, Brazil. Studies carried out from 1990 to 1995 . Revue d'Élevage et de Médecine Vétérinaire des Pays Tropicaux, v. 52, n. 1, p. 9-12, 1999.

VASCONCELOS, P. F. C.; TRAVASSOS DA ROSA, J. F. S.; TRAVASSOS DA ROSA, A. P. A.; DÉGALLIER, N.; PINHEIRO, F. P.; SÁ FILHO, G. V. Epidemiologia das encefalites por arbovírus na Amazônia Brasileira. Revista do Instituto de Medicina Tropical de São Paulo, v. 33, n. 6, p. 465-476, 1991. 